\title{
Prevalence of Visual Impairment and Associated Factors Among Primary Schoolchildren in Addis Ababa, Central Ethiopia
}

This article was published in the following Dove Press journal: Clinical Ophthalmology

\author{
Yemisrach Hailu' \\ Desta Hiko ${ }^{2}$ \\ Tamrat Shaweno (D) ${ }^{2}$ \\ 'Department of Ophthalmology, Minilik II \\ Referral Hospitaly, Addis Ababa, Ethiopia; \\ ${ }^{2}$ Department of Epidemiology, Faculty of \\ Public Health, Jimma University Institute \\ of Health, Jimma, Ethiopia
}

Background: Visual impairment (VI) refers to reduction of vision resulting in a lower than normal visual acuity (VA). Although school programs are recommended for early detection and timely interventions of VI, available information with regard to prevalence of VI and associated factors among primary schoolchildren near to the main city, Addis Ababa is inadequate. Thus, we assessed the prevalence of VI and the associated factors among children attending government primary schools of Lideta sub-city, Addis Ababa, Ethiopia.

Methods: This was a school-based cross-sectional study conducted from April to May 2019, using a two-stage cluster sampling method in Lideta sub-city, Addis Ababa, Ethiopia. From the total 18 government primary schools in Lideta sub-city, six were selected using probability proportionate to size (PPS) method. The study population was primary schoolchildren aged 7 to 17 years in the selected six primary schools. A total of 816 eligible primary schoolchildren were identified to be included in the study. The selected children were examined for the presence of VI. Children's parents/guardians were interviewed using structured pre-tested questionnaires. In this study, myopia and hyperopia were defined as difficulty in viewing distant and near objects, respectively. Similarly, astigmatism was a refractive error which results from an uneven cornea surface, which results in distorted images. Epi-data 3.1 and SPSS version 20 were used for data entry and analysis, respectively. Binary logistic regression was performed to check association between dependent and independent variables. Significance was set at $\mathrm{p}$-value $<0.05$.

Results: From a total of 816 eligible primary schoolchildren, 773 children were examined for VI, making the response rate $94.7 \%$. Out of the 773 children, $370(47.9 \%)$ were male and $403(52.1 \%)$ were female. The mean age of the participants was 11.69 years (SD 2.64 years). The prevalence of VI among schoolchildren was $4.4 \%$. The causes of VI included myopia (43\%), astigmatism with or without amblyopia (31\%), hyperopia with or without amblyopia (20\%), and others. The parents/ guardians not being aware of their children's eye problem (AOR $=2.2,95 \% \mathrm{CI}$ : $1.2-4.4)$ was the only significantly associated factor with VI.

Conclusion: In this study, the prevalence of VI among schoolchildren was high. The students being unaware about their eye problem was significantly associated with VI. Thus, close monitoring and regular screening for VI in schoolchildren are highly recommended to allow timely intervention.

Keywords: Ethiopia, prevalence, schoolchildren, visual impairment

\section{Introduction}

It was estimated that more than 285 million people were visually impaired globally by the end of $2013,{ }^{11}$ of which some 12.8 million were in the age group of 5-15. Each year an estimated 500,000 children are becoming blind, ${ }^{1}$ of which about
Correspondence: Tamrat Shaweno P.O. Box: 378, Jimma, Ethiopia Tel +25I-9l2-49-34-82

Email babiynos@gmail.com 
300,000 live in Africa. $^{2}$ The leading causes of VI are uncorrected refractive errors, cataract, age-related macular degeneration, glaucoma, diabetic retinopathy, corneal opacity and trachoma. ${ }^{3-5}$ Approximately $80 \%$ of VI globally is considered avoidable. In other words, it is either preventable or treatable. ${ }^{6,7}$ For example, in low-income countries congenital cataract is a leading cause, whereas in high income countries it is more likely to be retinopathy of prematurity. ${ }^{8}$ The prevalence of VI, low vision, and blindness in children in a country is related to the nutritional, health, and socioeconomic status of that country. ${ }^{9}$ Ethiopia is believed to have one of the world's highest rates of blindness (1.6\%) and low vision $(3.7 \%)$ in the general population, of which more than $80 \%$ is either treatable or preventable. ${ }^{10}$ Vision or eye sight refers to our ability or power to see. Vision can be measured both in children and adults using a variety of testing tools and this measured vision is called VA. The presence of excellent VA indicates the visual pathway is functioning well. ${ }^{11,12}$

The World Health Organization's (WHO's) International Classification of Diseases (ICD)-10 defines mild VI as "a corrected VA of $<6 / 12$ to $6 / 18$ in the better eye", low vision (LV) as "a corrected VA in the better eye of $<6 / 18(<20 / 63)$ down to and including 3/60 (20/400)". ${ }^{13}$ Recent findings propose that presenting visual acuity (VA with spectacles if worn) in addition to best-corrected VA ought to be reported in all population-based studies. ${ }^{14}$ Most individuals who have a presenting VA in the better eye of $<6 / 12$ down to and including 3/60 may require spectacles, cataract surgery, or other treatment to restore sight and assessment for low-vision interventions. $^{15}$

The adverse impact of childhood VI and blindness is enormous and can remain for life. ${ }^{16}$ Therefore, in children, VI can affect school performance and other functions, such as ability to safely participate in sports. ${ }^{17-20}$ Poor performance at school may affect the child's self-confidence and their future career and limit their future employment opportunities. ${ }^{20}$ It has considerable social, psychological, and economic implications for the patients and their caregivers. $^{21}$

Although some studies have been conducted in rural parts of Ethiopia with regard to VI, data are lacking on schoolchildren near the major cities. Thus, additional studies are essential to provide a national figure on the prevalence and associated factors of VI in schoolchildren in Ethiopia. In countries with high attendance of children in schools, school-based vision screening programs are important for early detection and timely interventions. ${ }^{22}$ Knowledge of the prevalence of VI and associated factors among schoolchildren in urban settings of Ethiopia adds more information in order to design and implement intervention strategies relevant to Ethiopia. Therefore, this study was aimed at determining the prevalence and associated factors of VI in schoolchildren in Ethiopia.

\section{Methods}

\section{Study Area and Period}

This was a school-based cross-sectional study conducted on schoolchildren in Lideta sub-city, Addis Ababa, Ethiopia from April to May 2019. Addis Ababa is the capital city of Ethiopia with an area of 540 square kilometers and 3.38 million inhabitants. The structure of power organization of the city includes the city government, 10 sub-cities, namely Arada, Addis Ketema, Kirkos, Lideta, Gulele, Kolfe-Keranyo, Nifas silk Lafto, Bole, and Akaki Kaliti. ${ }^{16}$ The number of children enrolled in primary schools in Addis Ababa for the 2018/2019 academic year was 45,8661 . In Lideta sub-city, there are 18 governmentowned and 11 privately-owned schools. There was a total of 16,172 schoolchildren enrolled in the regular program at the primary schools for 2019 academic year. Out of these, 10,640 schoolchildren were enrolled in government primary schools and the remaining 5,532 were enrolled in private, public and church schools.

\section{Sample Size Determination and Sampling Technique}

The sample size was determined by using a formula for single population proportion with $95 \%$ confidence interval, prevalence of VI at $9.5 \%$ from previous study, ${ }^{26} 3 \%$ ( $\alpha=0.03$ margin of error), design effect of 2 and by considering $10 \%$ non-response rate. The final calculated sample size was 816 . In this study two-stage cluster sampling method was used. Lideta sub-city was the primary sampling unit (PSU). Primary schools in Lideta sub-city were selected using proportional allocation to size method which became secondary sampling units (SSU). From 29 primary schools in Lideta sub-city, all the 18 government primary schools in Lideta sub-city were considered as clusters. The total number of children attending government primary schools was 10,640. Among these, $6(30 \%)$ primary schools were selected using probability sampling to size method and were included in the study. 
The first school was selected according to a random start $(\mathrm{RS})=28$ which were generated using excel command. The consecutive strata (schools) were identified using the formula to calculate the random number that falls in the cumulative sum corresponding to a school. Accordingly, six schools were selected and included in the study. The total number of children in the six selected schools was 5,148 . The total calculated sample size was allocated to each school proportional to the number of schoolchildren in each specific school. The sample allocated to each school was further proportionally allocated to each class in that specific school. Sampling interval (SI) was calculated for each class in the school and study units were selected until the allocated sample size was fulfilled. Schoolchildren enrolled in selected schools who were under the age of 18 years and the parents/guardians of whom gave their consent to participate were included in the study.

\section{Operational Definitions}

In this study, "schoolchild" was considered a student aged between 7-18 years who was attending school from grades 1 up to 8 in government schools. Similarly, presenting with VI was defined as presenting vision (with spectacles if worn) as worse than 6/12 Snellen in the better eye. Vision impairment refers to reduction of vision resulting in a lower than normal VA, ie, VA $<6 / 12$ but better or equal to $6 / 18$ in the better eye as measured using Snellen's chart. ${ }^{23}$ Low vision (LV) refers to a more severe form of visual reduction, ie, VA worse than $6 / 18$ and better than or equal to $3 / 60$ as measured using the Snellen's chart.

\section{Study Variables}

The major outcome variable of interest was prevalence of VI. Independent variables included were age of the child, sex of the child, family history of spectacle use, guardian occupation, parental marital status, parental education, family income, duration of TV watching, distance of TV watching, duration of mobile phone exposure, outdoor playing status, vision screening service availability and visit to eye care facility.

In this study, VI was considered when the VA was $6 / 12$ or worse in better eye, according to the international disease classification. Pinhole testing was used for every child who had VA $<6 / 6$ in either eye to check for the presence of refractive errors. ${ }^{24}$ In this study, myopia and hyperopia were defined as difficulty in viewing distant and near objects, respectively. Similarly, astigmatism was a refractive error which results from an uneven cornea surface, which results in distorted images.

\section{Data Collection Tool, Procedure and Quality Control}

Visual acuity testing was conducted by trained nurses who were staff members in an eye department of Minilik II Hospital. Since it was not possible to get Log Mar projectors and rooms in schools with standard lighting conditions, VA testing was conducted using standard 3 meter Snellen's VA charts outside classrooms under ambient lighting conditions. By convention, the right eye was tested first while the left eye was occluded. Eyes were tested separately and together and the findings were recorded on the recording form. The findings of VA testing were verified by an optometrist and therefore VA testing was done two times for children with no VI and three times for children with VI. Any child with a VA $<6 / 12$ was referred to the optometrist who repeated VA testing to confirm findings of trained nurses. For children confirmed to have VA $<6 / 12$, the optometrist did objective refraction using Retinoscope in a dark room. Children whose vision did not improve with glasses were referred to an ophthalmologist who did further eye examination using a magnifying Loupe with light and a Direct Ophthalmoscope to establish the cause of VI. Measurements were checked for the possible existence of variation. If variations existed, the source of variation was identified and corrected. The principal investigator supervised the VA measurement. Structured questionnaires were prepared first in English and then translated to Amharic and then translated back to English for consistency. Staff nurses who were currently working in an eye department were selected and were given training on study objective, sources of bias, ethical issues, and interview techniques. The questions included in the questionnaire for example included: "Are you aware of the child's problem with sight?" and "If yes, did you seek modern eye care service?". Consequently, the responses for example included: "1: Yes, 2: No". The questionnaire was pre-tested by taking $10 \%$ of the total sample in one primary school in Lideta sub-city which was not included in the study. Subsequently, the parents/ guardians of the examined children were interviewed. Based on the findings of the pre-testing, all the necessary adjustments in the process of data collection and revision of the questionnaires were made. These revised questionnaires were administered to parents/guardians of children who had undergone VA testing and eye examination in the 
selected six primary schools. The trained staff nurses administered the questionnaire by using face-to face interview technique and the process of questionnaire administration was supervised by the principal investigator. Each questionnaire was also checked for completeness, missed values and inconsistency of responses were manually cleaned up.

\section{Data Management and Analysis}

Data were entered using Epi-data and analyzed using SPSS version 20 statistical software. Frequency tables, graphs and descriptive summaries were used to describe the data. Variables with $\mathrm{P}$ values $\leq 0.25$ at bivariate regression analysis were entered into multivariate logistic regression analysis. Significance was declared at $P$-value $<0.05$ at $95 \%$ CI with the corresponding adjusted odds ratios (AORs).

\section{Results}

\section{Characteristics of Schoolchildren}

A total of 773 primary schoolchildren attending grades 1-8 were examined and included in this study making up a response rate of $94.7 \%$. The mean age of the children included in this study was 11.69 years $(\mathrm{SD}=2.64$ years). Out of the 773 children, 403 (52.1) were female and more than half $452(58 \%)$ were attending classes between grades 5 up to 8 [Table 1$]$.

\section{Socio-Demographic and Economic Characteristics of Parents/Guardians}

Among the interviewed 773 parents/guardians, nearly half, $410(53 \%)$, were mothers and nearly three fourths, 542 (70.1\%), were female with a mean parent/guardian age of 39.73 years $(\mathrm{SD}=6.5)$. The highest number of guardians/

Table I Selected Sociodemographic Characteristics of Primary Schoolchildren in Lideta Sub-City, Addis Ababa, Ethiopia, 2019

\begin{tabular}{|l|l|l|}
\hline Variables & Categories & n (\%) \\
\hline Children's age & & \\
& $7-11$ & $265(34.3)$ \\
& $12-17$ & $508(65.7)$ \\
\hline Children's sex & & \\
& Male & $375(48.5)$ \\
& Female & $398(51.5)$ \\
\hline Current grade & & $351(41.5)$ \\
& $1-4$ & $452(58.5)$ \\
\hline
\end{tabular}

parents, $532(68 \%)$, were married and more than one fourth, $212(27.4 \%)$, had primary education. The families' average monthly income ranged from ETB 100 to 7000 with a mean of 1619.2 Birr, among which more than four fifths were earning below 634 ETB [Table 2].

\section{Behavioral Related Factors of the Schoolchildren and Their Parents}

With regard to the parents'/guardians' awareness of VI in their child, the majority, 518 (67.0\%), of the parents/guardians were not aware of VI in their child and exactly one third, 255 (33.0\%), of the parents had reported some form of an eye problem which occurred in their children. Similarly, 618 (79.9\%) parents reported that they had no family history of an eye problem of distance vision. Concerning some other

Table 2 Socio-Demographic and Economic Characteristics of Parents/Guardians of Schoolchildren in Lideta Sub-City, Addis Ababa, Ethiopia, 2019

\begin{tabular}{|c|c|c|}
\hline Characteristics & Categories & n (\%) \\
\hline Age of the parent/guardian & Continuous & Continuous \\
\hline \multirow[t]{3}{*}{ Sex of the parent/guardian } & & \\
\hline & Male & $231(29.9)$ \\
\hline & Female & $542(70.1)$ \\
\hline \multirow[t]{5}{*}{ Marital status } & & \\
\hline & Single & $80(10.3)$ \\
\hline & Married & $542(68.8)$ \\
\hline & Divorced & $80(10.3)$ \\
\hline & Widowed & $81(10.5)$ \\
\hline \multirow[t]{6}{*}{ Educational status } & & \\
\hline & Illiterate & $153(19.8)$ \\
\hline & Literate & I33 (I7.2) \\
\hline & Primary & $212(27.4)$ \\
\hline & Secondary & $174(22.5)$ \\
\hline & College and above & $101(13.1)$ \\
\hline \multirow[t]{3}{*}{ Family size } & & \\
\hline & $<5$ & $516(66.8)$ \\
\hline & $5-10$ & $257(33.2)$ \\
\hline \multirow[t]{3}{*}{ Monthly income in ETB } & & \\
\hline & $<1650$ & $634(82.0)$ \\
\hline & $165 \mid-5250$ & $132(17.1)$ \\
\hline \multirow[t]{5}{*}{ Relationship with child } & & \\
\hline & Father & $184(23.8)$ \\
\hline & Mother & $410(53.0)$ \\
\hline & Sibling & $64(8.3)$ \\
\hline & Guardian & $115(14.9)$ \\
\hline
\end{tabular}

Abbreviation: ETB, Ethiopian birr. 
behavioral factors of the children, the parents reported that $657(85.0 \%)$ children played outdoors every day, more than two thirds, $690(89.3 \%)$, responded that their children watched TV every day and 299 (38.7\%) parents/guardians reported that their children did not play any video/mobile/PC games.

\section{Prevalence of Visual Impairment Among Schoolchildren}

According to the VA testing, 34 (4.4\%; 95\% CI: 3.0, 6.1) had VI of which $21(61.8 \%)$ were male. The causes of VI included: myopia (43.0\%), astigmatism (31.0\% [with amblyopia 38\%, without amblyopia (62\%)]), hyperopia (20.0\% [with amblyopia $16 \%$, without amblyopia $84 \%$ ]), and others like keratoconus and pseudophakia [Figure 1].

\section{Factors Associated with Visual Impairment}

During the binary logistic regression analysis; sex of the child, parental educational status and awareness status of VI in their child were included in the final model being candidates. In the multivariate logistic regression model, the only variable that showed significant association with VI was the parents'/guardians' awareness of VI in their child. Accordingly, parents/guardians who were not aware of VI in their child were more than two times likely to develop VI (AOR=2.2; 95\% CI, 1.2-4.4, $\mathrm{P}<0.029)$ [Table 3].

\section{Discussion}

To attain the WHO's and the International Agency for the Prevention of Blindness, addressing vision priority by 2020

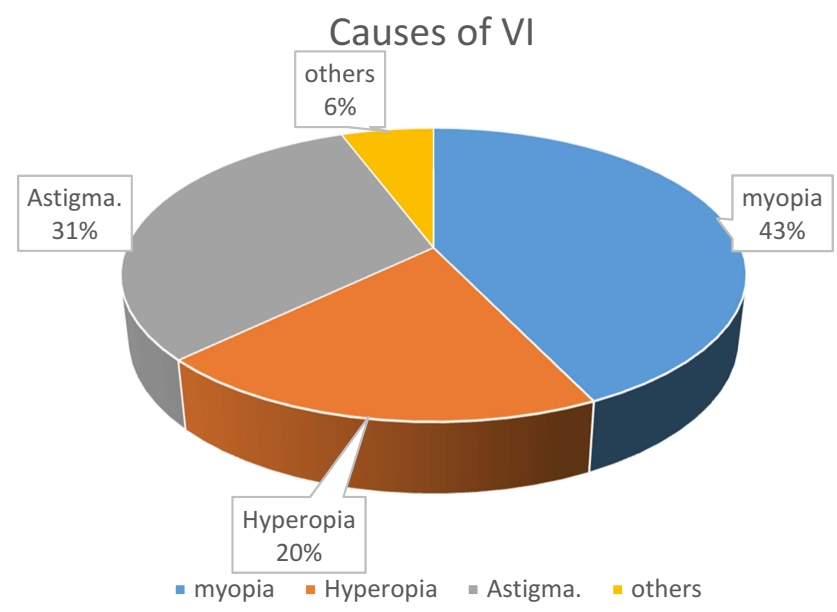

Figure I Causes of $\mathrm{VI}$ among schoolchildren in Lideta Sub-city, Addis Ababa, Ethiopia, 2019. and beyond is a priority. ${ }^{25}$ Accordingly, WHO recommends vision screening programs for primary schoolchildren., ${ }^{8,12}$ Thus, this study aimed to determine the prevalence and associated factors of VI among primary schoolchildren so as to generate evidence for decision makers to plan and implement prevention and management strategies.

In this study, the prevalence of VI was $4.4 \%$. Compared to other similar studies conducted so far, this finding was consistent ${ }^{26,27}$ and inconsistent with other studies conducted in different study settings. ${ }^{26,28,29}$ The observed variation could partly be explained by the differences in study setting, sample size, and age category of children included in the studies.

With regard to factors significantly associated with VI, there were a number of variables which showed significant association with VI in different literature, but not in this study. These included being female, being in the age group of 10-13 years, history of spectacle use by both parents, distance of TV watching, duration of TV watching, duration of computer/mobile games, watching television for 2-4 hrs/ day, watching television at $<1 \mathrm{~m}$, watching television at 1-2 m, mobile exposure for $2-4 \mathrm{hrs} /$ day, mobile exposure for $>4 \mathrm{hrs} /$ day, medical visit while experiencing symptoms and no medical visit experience and outdoor playing. ${ }^{28,30}$ The only variable that showed significant association with VI was the parents'/guardians' awareness status about VI in their children. Accordingly, parents/guardians being unaware of VI in their children were more likely to develop VI in their children compared to parents who were aware about VI in their children. Similar other studies conducted in Ireland $^{25}$ also suggested that societal factors which may influence access to eye care including lack of awareness of the importance of vision checks within the community may be positively associated with VI in children. Implementation of strategies to reduce vulnerability among children who require spectacles to see clearly or maintain ocular alignment can reduce VI among schoolchildren. In addition, streamlining and integration of strong empowerment programs including child eye health packages into other school health care packages can enhance the awareness level of all schoolchildren about good vision and how they should see from children's perspectives.

\section{Limitations of the Study}

Visual acuity testing was done using 3 meter Snellen acuity chart. The 6-meter Log-MAR chart was available but using this chart was challenged by space problems. The standard retro-illuminated Log-MAR projector was 
Table 3 Summary of Binary and Multivariate Logistic Regression Analysis of Factors Associated with VI Among Primary Schoolchildren in Lideta Sub-City, Addis Ababa, Ethiopia, 2019

\begin{tabular}{|l|l|l|l|l|l|}
\hline \multirow{2}{*}{ Characteristics } & \multicolumn{2}{|l|}{ Visual Impairment } & COR(95\% CI) & AOR(95\% CI) & P-value \\
\cline { 2 - 3 } & Yes & No & & & \\
\hline $\begin{array}{l}\text { Students' sex } \\
\text { Male }\end{array}$ & 21 & 354 & $1.76(0.9,3.6)$ & $1.72(0.8-3.5)$ & 0.137 \\
Female & 13 & 385 & 1.00 & 1.00 & 1.00 \\
\hline $\begin{array}{l}\text { Parental education } \\
\text { Illiterate }\end{array}$ & 5 & 148 & $0.54(0.1-0.2)$ & $0.61(0.2-2.0)$ & 0.417 \\
Literate & 7 & 126 & $0.21(0.1-0.8)$ & $0.62(0.2-1.8)$ & 0.385 \\
Primary & 11 & 201 & $0.02(0.1-1.7)$ & $0.62(0.2-2.0)$ & 0.399 \\
Secondary & 9 & 165 & $0.02(0.1-1.8)$ & $1.70(0.3-9.0)$ & 0.532 \\
College and above & 2 & 99 & 1.00 & 1.00 & \\
\hline Parental awareness of VI in their children & 17 & 238 & $2.10(1.1-4.2)$ & $2.17(1.2-4.4)$ & $0.029 *$ \\
Aware & 17 & 501 & 1.00 & 1.00 & \\
Not aware & & & & \\
\hline
\end{tabular}

Note: *Significant at $p$-value $<0.05$

Abbreviations: AOR, adjusted odds ratio; COR, crude odds ratio; VI, visual impairment.

not available in this study. The results of this survey can be used to calculate sample sizes for other studies but the true prevalence of VI can only be determined by school screening. In order to generalize the findings of this study to the city of Addis Ababa, it is necessary to conduct a similar study in two more randomly selected sub-cities.

\section{Conclusion}

In this study, the prevalence of VI among schoolchildren was high. Parental/guardians' lack of awareness of VI was associated with VI in their children. Thus, close monitoring and regular screening of schoolchildren for VI is recommended to ensure timely intervention.

\section{Declarations}

\section{Ethical Approval and Consent to Participate}

The study protocol was approved by the Institutional Review Board of Jimma University, Ethiopia, and Addis Ababa Regional Administration Educational Bureau, Addis Ababa, Ethiopia. Official letter of support was written by Education bureau to Lideta sub-city Administration Education office. Official support letters were written to seven primary schools which were included in pre-testing and the study. We also confirm that the study followed the Helsinki Declaration on human subjects. Written and signed consent and assent was obtained from parents/legal guardians to participate in the study and their respective children too. All parents/guardians of the children were given the information on the status of his/her child's eye health. For those children identified as having impaired vision or other problems, spectacles prescriptions, referrals to eye units, and all the necessary information were provided.

\section{Abbreviations}

Log-MAR, Logarithm of Minimum Angle of Resolution; PBL, Prevention of Blindness; VA, Visual Acuity; VCS, Vision Care Services; VI, Visual Impairment.

\section{Data Sharing Statement}

Available upon request.

\section{Acknowledgments}

Our special thanks go to Orbis Ethiopia for technical support and generosity to finance this research. We would like to acknowledge the executive committee of Ophthalmological Society of Ethiopia for allowing all the equipment necessary for eye examination without which the screening could not have taken place. We are also grateful to the students who participated in this study.

\section{Author Contributions}

All authors contributed to data analysis, drafting and revising the article, gave final approval of the version to be published, and agree to be accountable for all aspects of the work. 


\section{Funding}

This project was funded by Orbis Ethiopia.

\section{Disclosure}

Yemisrach Hailu reports grants from Orbis Ethiopia and non-financial support from Ophthalmological Society of Ethiopia during the conduct of the study. The authors declare that they have no other competing interests.

\section{References}

1. Gogate P, Kalua K, Court Right P. Blindness in childhood in developing countries: time for a reassessment? PLoS Med. 2019;84:1291-1297.

2. Wilkinson JM, Cozine EW, Kahn AR. Refractive eye surgery: helping patients make informed decisions about LASIK. Am Fam Physician. 2017;95(10):637-644.

3. Bourne RR, Dineen BP, Ali SM, Huq DM, Johnson GJ. Outcomes of cataract surgery in Bangladesh: results from a population based nationwide survey. $\mathrm{Br} J$ Ophthalmol. 2003;87(7):813-819. doi:10.1136/bjo.87.7.813

4. Cedrone C, Nucci C, Scuderi G, Ricci F, Cerulli A, Culasso F. Prevalence of blindness and low vision in an Italian population. Eye. 2006;20(6):661-667. doi:10.1038/sj.eye.6701934

5. Maberley DA, Hollands $\mathrm{H}$, Chuo J, et al. The prevalence of low vision and blindness in Canada. Eye. 2006;20(3):341-346. doi:10.1038/sj.eye.6701879

6. Vijaya L, George R, Asokan R, Velumuri L, Ramesh S. Prevalence and causes of low vision and blindness in an urban population: the Chennai Glaucoma study. Indian J Ophthalmol. 2014;62(4):477-481. doi:10.4103/0301-4738.111186

7. Robert M. Optometry. A model of the prevalence and incidence of low vision and blindness among adults in the U.S. Am Acad Optom Vis Sci. 2002;79(1):31-38.

8. Kavitha V, Balasubramanian P, Heralgi MM. Iris-claw versus posterior chamber fixation intraocular lens implantation in pediatric traumatic cataract. Taiwan J Ophthalmol. 2016;6(2):69-74. doi:10.1016/ j.tjo.2016.04.001

9. Gilbert C, Foster A. Childhood blindness in the context of VISION 2020 - the right to sight. Bull World Health Organ. 2001;79:227-232.

10. Berhane Y, Worku A, Bejiga A. National Survey on Blindness Low Vision and Trachoma in Ethiopia. Addis Ababa: Ophthalmological Society of Ethiopia, and the Ethiopian Federal Ministry of Health of Ethiopia; 2006.

11. Walker K, Hall WD, Hurst JW. Clinical Methods: The History, Physical, and Laboratory Examinations. 3rded. Boston: Butterworths; 1990. Available from: https://www.ncbi.nlm.nih.gov/ pubmed/21250045.Accessed March 4, 2020.

12. WHO. Visual Impairment and Blindness Fact Sheet. Geneva: World Health Organization (WHO); 2013.

13. Resnikoff S, Keys TU. Future trends in global blindness. Indian J Ophthalmol. 2012;60:387-395. doi:10.4103/0301-4738.100532

14. Resnikoff S, Pascolini D, Mariotti S, Pokharel GP. Global magnitude of visual impairment caused by uncorrected refractive errors in 2004. Bull World Health Organ. 2008;86(1):63-70. doi:10.2471/BLT.07.041210
15. Gilbert CE, Ellwein L. Prevalence and causes of functional low vision in school-age children: results from standardized population surveys in Asia, Africa, and Latin America. Invest Ophthalmol Vis Sci. 2008;49(3):877-881. doi:10.1167/iovs.07-0973

16. Padhye A, Khandekar R, Dharmadhikari S, Dole K, Gogate P, Deshpande M. Prevalence of uncorrected refractive error and other eye problems among urban and rural school children. Middle East Afr J Ophthalmol. 2009;16:69-77. doi:10.4103/0974-9233.53864

17. Melese M, Alemayehu W, Bayu S, et al. Low vision and blindness in adults in Gurage Zone, central Ethiopia. Br J Ophthalmol. 2003;87 (6):677-680. doi:10.1136/bjo.87.6.677

18. Entekume G, Patel J, Sivasubramaniam S, et al. Prevalence, causes, and risk factors for functional low vision in Nigeria: results from the national survey of blindness and visual impairment. Invest Ophthalmol Vis Sci. 2011;52(9):6714. doi:10.1167/iovs.11-7293

19. Zerihun N, Mabey D. Blindness and low vision in Jimma Zone, Ethiopia: results of a population-based survey. Ophthalmic Epidemiol. 1997;4:19-26. doi:10.3109/09286589709058057

20. Cherinet FM, Tekalign SY, Anbesse DH, Bizuneh ZY. Prevalence and associated factors of low vision and blindness among patients attending St. Paul's Hospital Millennium Medical College, Addis Ababa, Ethiopia. BMC Ophthalmol. 2018;18(1):232. doi:10.1186/s12886018-0899-7

21. Rahman MM, Rahman N, Foster PJ, et al. The prevalence of glaucoma in Bangladesh: a population based survey in Dhaka division. $\mathrm{Br}$ J Ophthalmol. 2004;88:1493-1497. doi:10.1136/bjo.2004.043612

22. World Health Organization. Blindness and Deafness Unit \& WHO Programme for the Prevention of Blindness. Elimination of Avoidable Visual Disability Due to Refractive Errors: Report of an Informal Planning Meeting. Geneva: World Health Organization; July 3-5, 2000. Available from: https://apps.who.int/iris/handle/10665/67800. Accessed March 4, 2020.

23. Encyclopedia Britannica 2006. Ultimate Reference Suite DVD. Eye. human Encyclopedia Britannica. 2008.

24. Elgohary AA, Abuelela MH, Eldin AA. Age norms for grating acuity and contrast sensitivity measured by Lea tests in the first three years of life. Int $J$ Ophthalmol. 2017;10(7):1150-1153. doi:10.18240/ ijo.2017.07.20

25. Harrington SC, Stack J, Saunders K, O'dwyer V. Refractive error and visual impairment in Ireland schoolchildren. $\mathrm{Br} J$ Ophthalmol. 2019;103(8):1112-1118. doi:10.1136/bjophthalmol-2018-312573

26. Mehari ZA, Yimer AW. Prevalence of refractive errors among schoolchildren in rural central Ethiopia. Clin Exp Optom. 2013;96 (1):65-69. doi:10.1111/cxo.2013.96.issue-1

27. Darge HF, Shibru G, Mulugeta A, Dagnachew YM. Prevalence of visual acuity impairment among school children in Arada Sub-City primary schools in Addis Ababa. Hindawi J Ophthalmol. 2017;7. doi:10.1155/2017/9326108

28. Kannan U, Rajendiran A, Yeraballi D, Shanmugavel K, John NA, Rene S. Refractive error and associated risk factors in 6-12 years schoolchildren. Natl J Physiol Pharm Pharmacol. 2016;6:554-558. doi:10.5455/njppp.

29. Omar R, Mohd W, Abdul HW, Knight VF. Prevalence of visual impairment in Orang Osli children, Malaysia. BMC Public Health. 2019;19:543-559. doi:10.1186/s12889-019-6865-3

30. Bezabih L, Abebe TW, Fite RO. Prevalence and factors associated with childhood visual impairment in Ethiopia. Clin Ophthalmol. 2017;11:1941-1948. doi:10.2147/OPTH.S135011 


\section{Publish your work in this journal}

Clinical Ophthalmology is an international, peer-reviewed journal covering all subspecialties within ophthalmology. Key topics include:

Optometry; Visual science; Pharmacology and drug therapy in eye diseases; Basic Sciences; Primary and Secondary eye care; Patient Safety and Quality of Care Improvements. This journal is indexed on PubMed
Central and CAS, and is the official journal of The Society of Clinical Ophthalmology (SCO). The manuscript management system is completely online and includes a very quick and fair peer-review system, which is all easy to use. Visit http://www.dovepress.com/ testimonials.php to read real quotes from published authors.

Submit your manuscript here: https://www.dovepress.com/clinical-ophthalmology-journal 